\section{Eleven-year Correlation of Physical Fruit Texture Traits between Computerized Penetrometers and Sensory Assessment in an Apple Breeding Program}

\author{
Soon Li Teh ${ }^{1}$, Lisa Brutcher ${ }^{1}$, Bonnie Schonberg ${ }^{1}$, \\ and Kate Evans ${ }^{1}$
}

AdDitional INDEX wORDs. crispness, firmness, hardness, Malus domestica

SUMMARY. Fruit texture is a major target of apple (Malus domestica) breeding programs due to its influence on consumer preference. This multitrait feature is typically rated using sensory assessment, which is subjective and prone to biases. Instrumental measurements have predominantly targeted firmness of the outer region of fruit cortex using industry standard Magness-Taylor-type penetrometers, while other metrics remain largely unused. Additionally, there have been limited reports on correlating sensory attributes with instrumental metrics on many diverse apple selections. This report is the first to correlate multiyear historical fruit texture information of instrumental metrics and sensory assessment in an apple breeding program. Through 11 years of routine fruit quality evaluation at the Washington State University apple breeding program, physical textural data of 84,552 fruit acquired from computerized penetrometers were correlated with sensory assessment. Correlations among various instrumental metrics are high $(0.63 \leq r \leq 1.00$; $P<0.0001)$. In correlating instrumental outputs with sensory data, there is a significant correlation $(r=0.43 ; P<0.0001)$ between the instrumental crispness value and sensory crispness. Additionally, instrumental hardness traits are significantly correlated $(0.61 \leq r \leq 0.69 ; P<0.0001)$ with sensory hardness. Outputs from two versions of computerized penetrometers were tested and shown to have no statistical differences. Overall, this report demonstrates potential use of instrumental metrics as firmness and crispness estimates for selecting apples of diverse backgrounds in a breeding program. However, in testing a large number and diversity of fruit, experimenters should perform data curation and account for lower limits/thresholds of the instrument.

$\mathrm{F}$ ruit texture is a major driver for consumer acceptance of apples [Malus domestica (Harker et al., 2003, 2006, 2008)], and it has been rated by United States apple producers as a priority trait in the development of a successful apple variety (Yue et al., 2013). In the past 2 decades, a wide range of studies have been carried out to characterize apple fruit texture variability (Ballabio

Received for publication 22 July 2020. Accepted for publication 21 Sept. 2020.

Published online 15 October 2020

${ }^{1}$ Tree Fruit Research and Extension Center, Washington State University, 1100 North Western Avenue, Wenatchee, WA 98801

We thank Nancy Buchanan for technical assistance with penetrometers and manuscript review, as well as Sarah Kostick for helpful discussion and manuscript review.

K.E. is the corresponding author. E-mail: kate evans@wsu.edu.

This is an open access article distributed under the CC BY-NC-ND license (https://creativecommons.org/ licenses/by-nc-nd/4.0/).

https://doi.org/10.21273/HORTTECH04698-20 et al., 2012; Chang et al., 2018; Charles et al., 2018; Cliff and Bejaei, 2018; Cliff and Toivonen, 2017; Costa et al., 2011; Harker et al., 2002, 2006; Luisa Demattè et al., 2014; Park et al., 2016; Piazza and Giovenzana, 2015; Zdunek et al., 2010, 2011; Zhao et al., 2017).

Fruit texture is a multitrait feature that encompasses mechanical (e.g., firmness and hardness) and acoustic (e.g., crispness) characteristics. These characteristics can be measured instrumentally using, commonly, a penetrometer (via puncture tests), routine sensory assessment (necessary throughput of a breeding program), or evaluation by trained sensory panelists. While there have been correlation studies (Cliff and Bejaei, 2018; Zdunek et al., 2010) on instrumental and sensory analyses, a multiyear large-scale examination of such correlation in diverse apple selections is lacking. Notwithstanding availability of correlation data, sensory assessment/evaluation can have shortcomings, such as subjectivity/ biases associated with contrast, habituation, and halo errors (Oraguzie et al., 2009), as well as reliance on experienced/trained panelists.

Since its inception in 1994, the Washington State University apple breeding program (WABP) has amassed fruit textural data (i.e., instrumental measurements and sensory assessment) through routine fruit evaluation of the breeding program seedlings and selections. The instrument used at WABP since 2009 is the Mohr Digi-Test (MDT1 and MDT-2; Mohr and Associates, Richland, WA), a computerized penetrometer for measuring firmness, hardness, and crispness (Evans et al., 2010). In 2010 and 2011, this instrument was also implemented on a national scale in the U.S. Department of Agriculture (USDA)-Specialty Crop Research Initiative (SCRI) RosBREED project (Evans et al., 2012; Schmitz et al., 2013).

This work expands on a previous framework established by Evans et al. (2010), but with 11 years of data as well as a transition from MDT-1 to MDT-2 (successor to MDT-1) instruments. As previously summarized by Mohr and Mohr (2007) and Evans et al. (2010), the penetrometer measures force encountered by a test plunger based on a preset trajectory of displacement, velocity, and acceleration. For apples, calculations were made using a two-region model of a fruit. Region l (Rl) extends to a fixed depth of 0.32 inch from the outermost region of fruit (Mohr and Mohr, 2007), and is the region measured with industry standard Magness-Taylor-type penetrometers (Abbott, 1994; Magness and Taylor,

\begin{tabular}{llll}
\hline $\begin{array}{l}\text { Units } \\
\text { To convert U.S. to SI, } \\
\text { multiply by }\end{array}$ & U.S. unit & SI unit & $\begin{array}{l}\text { To convert SI to U.S., } \\
\text { multiply by }\end{array}$ \\
\hline 25.4 & inch $(\mathrm{es})$ & $\mathrm{mm}$ & 0.0394 \\
0.4536 & $\mathrm{lb}$ & $\mathrm{kg}$ & 2.2046 \\
$\left({ }^{\circ} \mathrm{F}-32\right) \div 1.8$ & ${ }^{\circ} \mathrm{F}$ & ${ }^{\circ} \mathrm{C}$ & $\left({ }^{\circ} \mathrm{C} \times 1.8\right)+32$
\end{tabular}


1925). Region 2 (R2) extends from $\mathrm{Rl}$ to an arbitrary depth proportional to $30 \%$ diameter of fruit (Mohr and Mohr, 2007), representing the bulk of edible material. Because apples soften from the inside out, measurements at R2 are likely more indicative of fruit integrity. Metrics or outputs from constant-velocity tests include average hardness at $\mathrm{Rl}(\mathrm{Al})$, average hardness at R2 (A2), maximum hardness at Rl (Ml), and maximum hardness at R2 (M2) (Mohr and Mohr, 2007). Force at the end of R2 (E2) estimates force at the R2 endpoint and is likely the first measurement to indicate internal softening (Mohr and Mohr, 2007). Two overall force metrics are overall average hardness $(\mathrm{OAH})$ and overall maximum hardness $(\mathrm{OMH})$. At the $\mathrm{R} 1-\mathrm{R} 2$ boundary, constant-velocity testing is briefly interrupted by a constant-force or creep deformation $(\mathrm{C} 0)$ test, which measures displacement (or push back) of the plunger under $10 \mathrm{lb}$ of constant force for a preset duration (Mohr and Mohr, 2007). Instrumental crispness, reported as a unitless $\mathrm{Cn}$, is a calculated value that estimates the energy released during fruit tearing, similar to the energy released during a bite (Mohr and Mohr, 2007).

This study uses data collected from the WABP's routine fruit quality evaluation over the past 11 years. With textural data amassed through instrumental measurements and sensory assessment, the overall objectives of this work are to: 1) determine correlations between penetrometer outputs and sensory attributes, 2) assess correlations among sensory attributes, and 3) identify statistical differences in penetrometer outputs when transitioning from MDT-1 to MDT-2 devices.

\section{Materials and methods}

Experimental material. From 2009 to $2019,84,552$ apple fruit were harvested from five main WABP evaluation orchards in central Washington. This data set represents all fruit sampled as part of WABP's routine evaluation of seedling fruit quality. Up to 30 fruit per selection/ variety were harvested weekly as their starch levels approximated three to five, based on the Cornell starchiodine index (Blanpied and Silsby, 1992); and harvested over 3 to 4 consecutive weeks per selection/variety, because the optimum harvest parameters for each selection are unknown. Fruit samples were stored at 1 to $2{ }^{\circ} \mathrm{C}$, and evaluated $\mathrm{l}$ ) within $\mathrm{l}$ week of harvest ( $\mathrm{n}=$ up to 10 fruit per selection/variety and harvest), 2) after 2 months of cold storage followed by $\mathrm{l}$ week of equilibration at $25^{\circ} \mathrm{C}$ $(\mathrm{n}=10$ fruit per selection/variety and harvest), or 3 ) after 4 months of cold storage followed by 1 week of equilibration at $25^{\circ} \mathrm{C}(\mathrm{n}=10$ fruit per selection/variety and harvest).

INSTRUMENTAL MEASUREMENTS. Computerized penetrometers, MDT1 (used in 2009 through 2013) and MDT-2 (used from 2014 onwards), were used to measure instrumental traits of harvested fruit. Texture analysis was carried out on an intermediate (between sun and shade) side of each fruit that had been peeled, yielding instrumental outputs including $\mathrm{Al}$, $\mathrm{C} 0, \mathrm{Cn}, \mathrm{E} 2, \mathrm{Ml}, \mathrm{OAH}$, and $\mathrm{OMH}$, as described above and by Mohr and Mohr (2007) and Evans et al. (2010). Additionally, the devices were used to determine fruit diameter and fruit weight. Note that instrumental outputs were acquired on an individual fruit basis for a subset of five fruit per harvest and storage duration for each selection/variety.

Before statistical analysis, the data set was curated to remove spurious data points. Fruit weight with negative values were reassigned as non-applicable (NA) instead of totally discarded, because the weighing device was independent of the penetrometer. Meanwhile, fruit with diameter less than 1.5 inches were completely discarded from the analysis, in adherence to MDT standard calculations associated with determining $\mathrm{Rl}$ and R2 of apple fruit (Mohr and Mohr, 2007). Because $\mathrm{Cn}$ is a trait calculated rather than measured, values beneath a threshold of 10 were reassigned as NA instead of discarded. For other penetrometer traits (e.g., Al, E2, OAH) with negative values, the entire sample (i.e., individual fruit) was discarded from further analysis.

Before the WABP's transition from MDT-1 to MDT-2 devices in 2013-14, a separate assessment of 127 fruit (independent of this data set) was performed to determine any statistical difference between outputs of the two penetrometers. Two intermediate sides of each fruit were peeled; one side was measured with MDT-1, and the other side with MDT-2. Instrumental outputs from these devices were subsequently analyzed with one-way analysis of variance (ANOVA).

Sensory assessment. As previously described by Evans et al. (2010), four core and long-term members of the WABP team used a list of predefined sensory attributes to assess a subset of five fruit from each harvested sample/selection $(\mathrm{n}=$ 17,261). Sensory texture attributes, such as crispness and hardness, followed similar descriptions in Harker et al. (2002) and were summarized in Evans et al. (2010). Succinctly, "crispness" is described as an acoustic sensation detected by the ear during food tearing or biting, while "hardness" is described as force exerted to completely bite through a sample between molars (Evans et al., 2010). An overall "eating quality" metric integrates all textural properties as well as acidity, aroma, and sweetness. Fruit were taken out of cold storage and equilibrated at room temperature. They were arranged as randomized intact whole-fruit samples (a second subset of five fruit) for panelist tasting, as part of WABP routine sensory assessment. Crispness and hardness were scored on a scale of 1 to 5 , with reference to 'Gala' having a standard score of 3. Eating quality was rated on a 9-point scale with 'Gala' having an intermediate score of 5 . Sensory scores from the four team members were averaged before statistical analysis. Note that sensory ratings were determined on each pooled sample of five fruit.

Statistical analysis. Following data curation to remove spurious data, instrumental outputs from 84,044 individual fruit were analyzed with Spearman's rank correlation. Then, instrumental outputs from each set of five fruit were averaged and correlated with sensory data using Spearman's rank correlation (necessary because instrumental measurements were acquired on individual fruit, while sensory fruit assessment was performed on a sample of five apples). Spearman's correlation coefficients range from -1 to 1 , indicating strengths of rank-based correlations of nonparametric data. Spearman's rank 


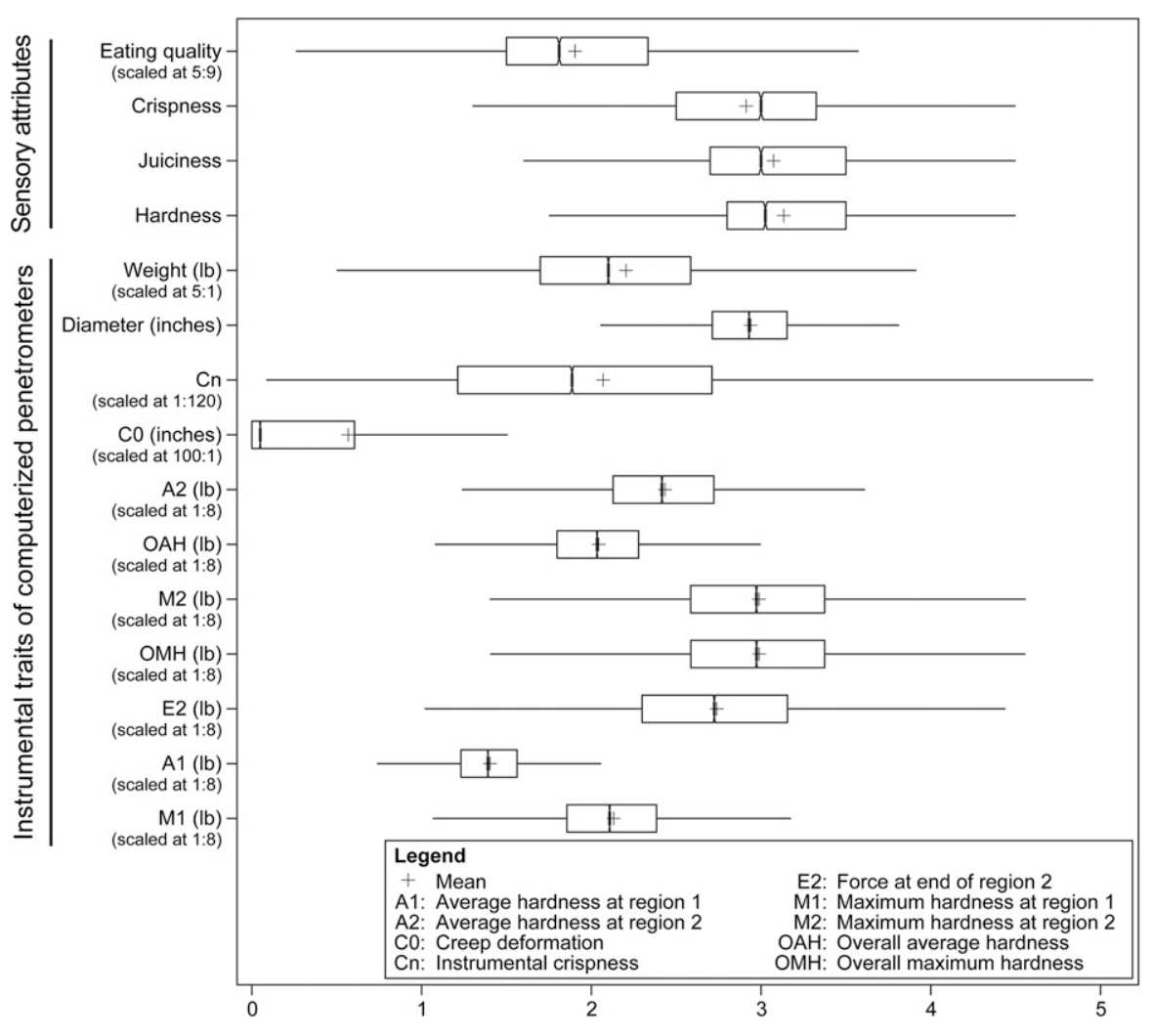

Fig. 1. Boxplots of sensory attributes and instrumental traits for 84,044 apple fruit harvested from 2009 to 2019 . Instrumental traits were measured using computerized penetrometers. Scaling, where noted in parentheses, was applied on several boxplots for $x$-axis fitting; $1 \mathrm{lb}=0.4536 \mathrm{~kg}, 1$ inch $=2.54 \mathrm{~cm}$.

Table 1. One-way analysis of variance results $(n=127$ apple fruit $)$ for statistical significance between an intermediate side measured with computerized penetrometer (Mohr Digi-Test; Mohr and Associates, Richland, WA) model one (MDT-1), and another intermediate side of the same fruit measured with model 2 (MDT-2).

\begin{tabular}{lcc}
\hline Trait & $P>\mathbf{F}$ & Significance \\
\hline Average hardness at region 1 (A1) & 0.966 & NS \\
Average hardness at region 2 (A2) & 0.995 & NS \\
Creep deformation (C0) & 0.964 & NS \\
Crispness $(\mathrm{Cn})$ & 0.952 & NS \\
Force at the end of region 2 (E2) & 0.988 & NS \\
Fruit diameter & 0.992 & NS \\
Fruit weight & 1.000 & NS \\
Maximum hardness at region 1 (M1) & 0.988 & NS \\
Maximum hardness at region 2 (M2) & 0.978 & NS \\
Overall average hardness (OAH) & 0.989 & NS \\
Overall maximum hardness (OMH) & 0.978 & NS \\
\hline
\end{tabular}

NS = nonsignificant.

correlation was chosen due to its suitability to analyze non-normally distributed variables/traits, such as instrumental crispness. Statistical significance of coefficients at error probability $(\alpha=0.01)$ was determined for this large data set.

In a separate analysis, ANOVA was performed to ascertain any "reshape2" version 1.4.4 (Wickham, 2012) for hierarchical clustering order and heatmap display. All figures were processed and rendered in Adobe Illustrator CS2 (Adobe, San Jose, CA). In particular, the Spearman's correlation coefficients from individual instrumental outputs were combined with coefficients from sensory data.

\section{Results and discussion}

Texture range. From the original set of 84,552 fruit measured on penetrometers, 508 data points (or $0.006 \%$ ) were erroneous and discarded from further analysis due to negative values in nonnegative traits or fruit diameter beneath threshold. In particular, 53 fruit with diameter below 1.5 inches were omitted from further analysis. In addition, 326, 84, 1 , and 44 fruit were discarded due to negative values in $\mathrm{Al}, \mathrm{E} 2, \mathrm{M} 2$, and $\mathrm{OAH}$, respectively. Stepwise culling of erroneous data points yielded a final discard of 508 out of 84,552 fruit. All analyses beyond this step used data from 84,044 fruit.

Erroneous values for traits extrinsic to penetrometers were reassigned instead of discarded. For instance, 164 fruit with reported negative weights were assigned as NA because weight measurement was not an inherent component of penetrometer trait measurements. Additionally, 486 data points with $\mathrm{Cn}$ below 10 (mostly 0) were reassigned as NA to account for possible penetrometer miscalculation of the crispness parameter.

Wide ranges in texture traits were observed throughout 11 years of fruit texture analysis (Fig. 1). Instrumental $\mathrm{Cn}$ values ranged from 11 to $1481($ mean $=248)$, while sensory crispness ranged from 1 to 5 (mean $=$ 2.91).

In transitioning from MDT- 1 to MDT-2, ANOVA results for 127 fruit indicated no statistical difference between outputs of these devices, with probability values ranging from 0.952 to 1 (Table 1). Minor, statistically insignificant differences may be due to a difference between the two intermediate sides, with one intermediate side measured with MDT-1 and the opposite side with MDT-2.

Correlations. In general, correlation coefficients among most 

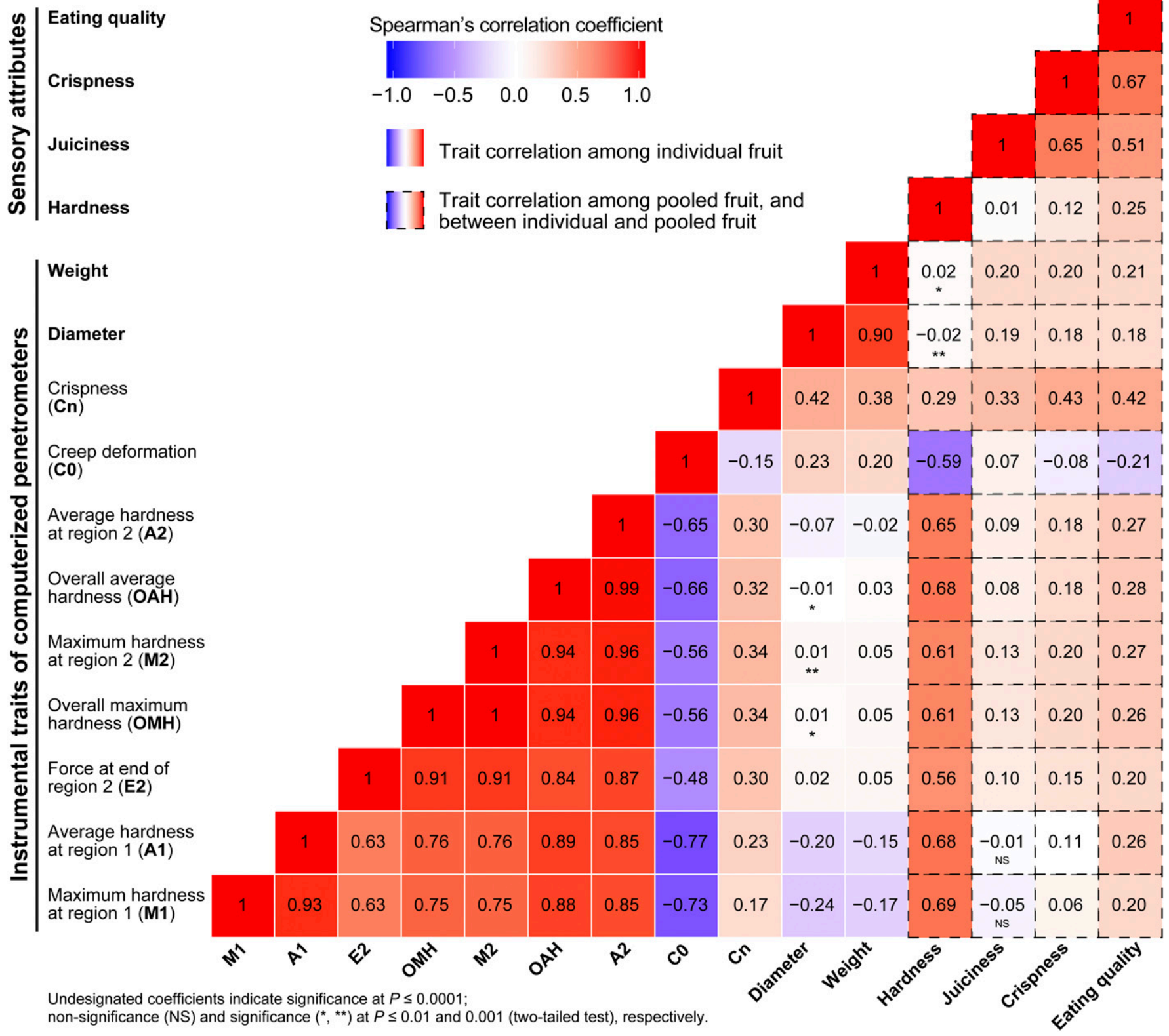

Fig. 2. Spearman's rank correlations of sensory assessment and textural measurements from computerized penetrometers for 84,044 apple fruit harvested from 2009 to 2019. Regular, undashed boxes indicate correlation coefficients between instrumental traits measured on individual fruit. Dashed boxes indicate correlation coefficients between instrumental and sensory traits measured as an average of five fruit per sample.

instrumental metrics are relatively high. $\mathrm{Al}, \mathrm{A} 2, \mathrm{E} 2, \mathrm{Ml}, \mathrm{M} 2, \mathrm{OAH}$, and $\mathrm{OMH}$ are highly correlated with one another, with coefficients ranging from 0.63 to 1.00 (Fig. 2). In contrast, C0 or "sponginess" is uncorrelated or negatively correlated (as expected) with other instrumental traits (Fig. 2).

In correlating instrumental metrics with sensory attributes, several trends are captured in Fig. 2. First, the instrumental $\mathrm{Cn}$ value is moderately correlated with sensory crispness $(r=0.43 ; P \leq 0.0001)$ as well as sensory eating quality $(r=0.42 ; P \leq$ $0.0001)$. However, sensory eating quality is more highly correlated with sensory crispness $(r=0.67 ; P \leq$ $0.0001)$ than with instrumental $\mathrm{Cn}$ value. In addition, sensory eating quality is moderately correlated with sensory juiciness $(r=0.5 \mathrm{l} ; P \leq$ 0.0001 ), which is consistent with the WABP's selection for apples with high juiciness.

The moderate correlation between sensory crispness and instrumental crispness can be attributed to many factors. From a statistical perspective, the sensory crispness metric is a narrow five-point scale, while instrumental crispness has a wide range (i.e., this data set ranges from 11 to 1481 ) due to its algorithmic estimation. Additionally, human perception of crispness is influenced by other characteristics, such as juiciness (i.e., burst of juice during a bite), of which a moderately high correlation is reported in our analysis $(r=0.65 ; P$ $<0.0001)$. By comparison, instrumental 
crispness is estimated by power output or energy released during fruit tearing (Mohr and Mohr, 2007).

In comparing perceived sensory traits, crispness is moderately correlated with juiciness $(r=0.65)$. This is consistent with previous findings by Evans et al. (2010) and Zdunek et al. (2010), reporting coefficients of $0.611(\mathrm{n}=1270$ apples $)$ and 0.642 $(\mathrm{n}=710$ apples $)$, respectively, but was lower than $0.832(\mathrm{n}=216$ apples $)$ found by Cliff and Bejaei (2018). The smaller sample size and genetic diversity in the study by Cliff and Bejaei (2018) likely resulted in a higher correlation coefficient.

Meanwhile, correlations of sensory crispness-hardness across studies were vastly different. In this work, sensory crispness is uncorrelated with sensory hardness $(r=0.12)$, whereas coefficients of $0.922,0.552$, and 0.879 were reported by Cliff and Bejaei (2018), Evans et al. (2010), and Zdunek et al. (2010), respectively. Coefficient differences in these studies can be attributed to the number of samples, orchard locations, orchard management, as well as the changing composition of genetic resources across the years of the study. Furthermore, the addition and enrichment of 'Honeycrisp' (a crisp but not firm apple) as a breeding parent in the program likely resulted in a dissociation between crispness and hardness/firmness (data not shown).

Aside from the $\mathrm{Cn}$ value, other instrumental measurements appear to be weakly or not correlated with sensory traits, except for sensory hardness. For instance, instrumental average hardness- $\mathrm{Al}$ and $\mathrm{A} 2$-is moderately correlated with sensory hardness, with coefficients of 0.68 and 0.65 , respectively. In addition, instrumental maximum firmness$\mathrm{Ml}$ and $\mathrm{M} 2$ - is also moderately correlated with sensory hardness, with coefficients of 0.69 and 0.61 , respectively. The moderate correlation between sensory and instrumental hardness is likely explained by the toughness of the peel in some sensory assessment samples. While penetrometer measurements were taken on peeled samples, sensory assessment could include tasting of fruit with and without a peel to obtain a more comprehensive assessment of eating quality. Samples with a tougher peel undoubtedly affected the sensory perception of flesh firmness. These correlation coefficients are lower than those reported in other studies (Cliff and Bejaei, 2018; Zdunek et al., 2010). For instance, Cliff and Bejaei (2018) reported that correlations between sensory hardness and $\mathrm{Al}, \mathrm{A} 2$, $\mathrm{Ml}$, and M2 were $0.860,0.921$, 0.857 , and 0.897 , respectively. Aside from differences in numbers and diversity of genotypes tested, a key distinction is that sensory evaluations in Cliff and Bejaei (2018) and Zdunek et al. (2010) were performed by trained sensory panelists (i.e., 10 panelists in either study). By comparison, routine sensory assessment at WABP relied on four members that, while experienced and familiar with the apple seedlings and selections, were routinely tasting up to 100 samples at a time to meet the necessary throughput of the breeding program. This likely resulted in palate and mental fatigue throughout the course of assessment.

In both instrumental metrics (i.e., average hardness and maximum firmness), it is worth noting that sensory hardness is marginally more correlated with instrumental pressure readings in $\mathrm{Rl}$ than in $\mathrm{R} 2$. These results differ from reports by Evans et al. (2010) as well as Cliff and Bejaei (2018). Evans et al. (2010) noted that sensory hardness was marginally more correlated with M2 (0.698) than Ml (0.661). Similarly, Cliff and Bejaei (2018) noted that sensory hardness was marginally more correlated with pressure readings in $\mathrm{R} 2$ than in $\mathrm{Rl}$, with correlation coefficients of 0.860 vs. 0.921 (Al vs. A2) and 0.857 vs. 0.897 (M1 vs. M2). Once again, discrepancies between these studies are most likely attributed to the number and diversity of genotypes tested.

\section{Conclusions}

Fruit texture is one of the most important breeding targets in apple breeding programs worldwide. The ability to describe, compartmentalize, and phenotype apple textural traits with reasonable accuracy using an instrument can remove breeders' subjectivity during the selection process.

In this work, we report an 11-year correlation of 84,044 apple textural data collected from computerized penetrometer and sensory assessment in
WABP. The Cn value, an instrumental estimate of crispness, is moderately correlated with sensory crispness, and this value can potentially be used as a crispness selection metric in a breeding program. Another important sensory textural attribute is hardness, which is moderately correlated with instrumental average hardness (i.e., $\mathrm{Al}$ and $\mathrm{A} 2$ ) as well as instrumental maximum firmness (i.e., $\mathrm{Ml}$ and M2).

In a longstanding breeding program where transition between instruments was inevitable, the shift from MDT-1 to MDT-2 devices was analyzed, and results showed no statistical differences between outputs of these instruments. Given the diversity of seedlings/selections and number of fruit tested, the use of a computerized penetrometer in collecting physical texture data of apples has yielded consistent and reliable instrumental outputs that can be correlated with sensory assessment, and thus this method can potentially replace the need for subjective testing.

Caution must be taken when evaluating a large number and diversity of fruit, as demonstrated in this work of 84,552 apples. Data curation to exclude nonsensible negative and zero values must be performed before any downstream statistical analysis. Additionally, lower limits/thresholds of fruit diameter should be considered, to account for displacement distance traveled by a penetrometer probe in determining $\mathrm{Rl}$ and $\mathrm{R} 2$.

\section{Literature cited}

Abbott, J.A. 1994. Firmness measurement of freshly harvested 'Delicious' apples by sensory methods, sonic transmission, Magness-Taylor, and compression. J. Amer. Soc. Hort. Sci. 119:510-515, doi: 10.21273/ jashs.119.3.510.

Ballabio, D., V. Consonni, and F. Costa. 2012. Relationships between apple texture and rheological parameters by means of multivariate analysis. Chemometr. Intell. Lab. 111:28-33, doi: 10.1016/ j.chemolab.2011.11.002.

Blanpied, G.D. and K. Silsby. 1992. Predicting harvest date windows for apples. Cornell Univ. Info. Bul. 221. https:// hdl.handle.net/1813/3299.

Chang, H.Y., Z.M. Vickers, and C.B. Tong. 2018. The use of a combination of instrumental methods to assess change in sensory crispness during storage of a 'Honeycrisp' apple breeding family. J. 
Texture Stud. 49:228-239, doi: 10.1111/ jtxs.12325.

Charles, M., M.L. Corollaro, L. Manfrini, I. Endrizzi, E. Aprea, A. Zanella, L. Corelli Grappadelli, and F. Gasperi. 2018. Application of a sensory-instrumental tool to study apple texture characteristics shaped by altitude and time of harvest. J. Sci. Food Agr. 98:1095-1104, doi: $10.1002 /$ jsfa. 8560 .

Cliff, M.A. and P.M. Toivonen. 2017. Sensory and quality characteristics of 'Ambrosia' apples in relation to harvest maturity for fruit stored up to eight months. Postharvest Biol. Technol. 132:145-153, doi: 10.1016/j.postharvbio.2017.05.015.

Cliff, M.A. and M. Bejaei. 2018. Intercorrelation of apple firmness determinations and development of crossvalidated regression models for prediction of sensory attributes from instrumental and compositional analyses. Food Res. Intl. 106:752-762, doi: 10.1016/j.foodres.2018.01.041.

Costa, F., L. Cappellin, S. Longhi, W. Guerra, P. Magnago, D. Porro, C. Soukoulis, S. Salvi, R. Velasco, F. Biasioli, and F. Gasperi. 2011. Assessment of apple (Malus $\times$ domestica Borkh.) fruit texture by a combined acoustic-mechanical profiling strategy. Postharvest Biol. Technol. 61:21-28, doi: 10.1016/j.postharvbio.2011.02.006.

Evans, K., L. Brutcher, B. Konishi, and B. Barritt. 2010. Correlation of sensory analysis with physical textural data from a computerized penetrometer in the Washington State University apple breeding program. HortTechnology 20:1026-1029, doi: 10.21273/hortsci.20.6.1026.

Evans, K., J. Luby, S. Brown, M. Clark, Y. Guan, B. Orcheski, C. Schmitz, C. Peace, E. van de Weg, and A. Iezzoni. 2012. Large-scale standardized phenotyping of apple in RosBREED. Acta Hort.
945:233-238, doi: 10.17660/ActaHortic.2012.945.31.

Harker, F.R., J. Maindonald, S.H. Murray, F.A. Gunson, I.C. Hallett, and S.B. Walker. 2002. Sensory interpretation of instrumental measurements 1 : Texture of apple fruit. Postharvest Biol. Technol. 24:225-239, doi: 10.1016/S09255214(01)00158-2.

Harker, F.R., F.A. Gunson, and S.R. Jaeger. 2003. The case for fruit quality: An interpretive review of consumer attitudes, and preferences for apples. Postharvest Biol. Technol. 28:333-347, doi: 10.1016/S0925-5214(02)00215-6.

Harker, F.R., R.L. Amos, G. Echeverríaa, and F.A. Gunson. 2006. Influence of texture on taste: Insights gained during studies of hardness, juiciness, and sweetness of apple fruit. J. Food Sci. 71:S77S82, doi: 10.1111/j.1365-2621.2006. tb08925.x.

Harker, F.R., E.M. Kupferman, A.B. Marin, F.A. Gunson, and C.M. Triggs. 2008. Eating quality standards for apples based on consumer preferences. Postharvest Biol. Technol. 50:70-78, doi: 10.1016/j.postharvbio.2008.03.020.

Luisa Demattè, M., N. Pojer, I. Endrizzi, M.L. Corollaro, E. Betta, E. Aprea, M. Charles, F. Biasioli, M. Zampini, and F. Gasperi. 2014. Effects of the sound of the bite on apple perceived crispness and hardness. Food Qual. Prefer. 38:58-64, doi: 10.1016/j.foodqual.2014.05.009.

Magness, J.R. and G.F. Taylor. 1925. An improved type of pressure tester for the determination of fruit maturity. U.S. Dept. Agr. Circ. No. 350.

Mohr, B.C. and C.L. Mohr. 2007. MOHR DIGI-TEST Computer-controlled fruit quality testing system: Manual for software version 1.25. 4 June 2020. <http://www.mohr-engineering. com/download.php?download_file $=$ MDT 1\%20Operators\%20Manual>.

Oraguzie, N., P. Alspach, R. Volz, C. Whitworth, C. Ranatunga, R. Weskett, and R. Harker. 2009. Postharvest assessment of fruit quality parameters in apple using both instruments and an expert panel. Post- harvest Biol. Technol. 52:279-287, doi: 10.1016/j.postharvbio.2009.01.004.

Park, D.J., Y.G. Chun, S.H. Lee, S.J. Lee, and B.K. Kim. 2016. Development of teeth probe for analysis of correlation between mechanical and sensory properties of apples. J. Texture Stud. 47:523529, doi: $10.1111 /$ jtxs.12195.

Piazza, L. and V. Giovenzana. 2015. Instrumental acoustic-mechanical measures of crispness in apples. Food Res. Intl. 69:209-215, doi: $10.1016 / j$.foodres.2014.12.041.

Schmitz, C.A., M.D. Clark, J.J. Luby, J.M. Bradeen, Y. Guan, K. Evans, B. Orcheski, S. Brown, S. Verma, and C. Peace. 2013. Fruit texture phenotypes of the RosBREED US apple reference germplasm set. HortScience 48:296-303, doi: 10.21273/hortsci.48.3.296.

Yue, C., R.K. Gallardo, J. Luby, A. Rihn, J.R. McFerson, V. McCracken, D. Bedford, S. Brown, K. Evans, C. Weebadde, and A. Sebolt. 2013. An investigation of U.S. apple producers' trait prioritizationEvidence from audience surveys. HortScience 48:1378-1384, doi: 10.21273/ hortsci.48.11.1378.

Wickham, H. 2012. reshape2: Flexibly reshape data: A reboot of the reshape package. $\mathrm{R}$ package version 1. I Mar. 2020. <https://cran.ms.unimelb.edu. au/web/packages/reshape2>.

Wickham, H. 2016. ggplot2: Elegant graphics for data analysis. Springer-Verlag, New York, NY.

Zdunek, A., J. Cybulska, D. Konopacka, and K. Rutkowski. 2010. New contact acoustic emission detector for texture evaluation of apples. J. Food Eng. 99:83-91, doi: 10.1016/j.jfoodeng.2010.02.002.

Zdunek, A., J. Cybulska, D. Konopacka, and K. Rutkowski. 2011. Evaluation of apple texture with contact acoustic emission detector: A study on performance of calibration models. J. Food Eng. 106:8087, doi: 10.1016/j.jfoodeng.2011.04.011.

Zhao, W., Y. Fang, Q.A. Zhang, Y. Guo, G. Gao, and X. Yi. 2017. Correlation analysis between chemical or texture attributes and stress relaxation properties of 'Fuji' apple. Postharvest Biol. Technol. 129:45-51, doi: 10.1016/j.postharvbio. 2017.03.010. 